\title{
PENGUKURAN KINERJA ORGANISASI BERDASARKAN KRITERIA MALCOLM BALDRIGE DI FASILITAS KESEHATAN TINGKAT PERTAMA NON PERAWATAN KOTA SURABAYA
}

\author{
MEASUREMENT OF ORGANIZATION PERFORMANCE BASED ON MALCOLM \\ BALDRIGE CRITERIA IN FIRST LEVEL HEALTHCARE FACILITES NON TREATMENT \\ OF SURABAYA CITY
}

\author{
Khairul Helmi ${ }^{1}$ \\ ${ }^{1}$ Fakultas Kesehatan Masyarakat, Universitas Airlangga, Surabaya \\ Email: helmysaudagar@gmail.com
}

\begin{abstract}
Service quality aspect is necessary because it reflects the level of success FKTP Non Treatment Surabaya City. To determine the quality requires any performancemeasurement. The objective of this study was to measure the performance of FKTP Non Treatment Surabaya City. This study was observational with cross sectional design. Performance measurement of FKTP Non Treatment Surabaya City consists of two types, namely FKTP Non Treatment with ISO standards and FKTP Non Treatment Non-ISO. Several samples from both FKTP Non treatmentswere randomly selected from several FKTPs, then asked to assess by filling out questionnaire. The study results were assessed based on several aspects, namely human resources, financial aspects, organizational culture, facilitiy support services, health policy, FKTPchallenges, public relations, servicethreats, technology and facilities, medical care facilities, and the service programschallenges. On FKTP ISO standards the highest value was similar to FKTP Non ISO namely Organizational Culture criteria with successive values of $91.73 \%$ and $86.79 \%$. So do the lowest value, namely the threat to service with $56.11 \%$ for FKTP ISO and $64.68 \%$ for FKTP Non-ISO.It can be concluded that based on Malcolm Baldrige criteria, FKTP ISO performance which obtained $87.25 \%$ was higher than FKTP non ISO which obtained $80.83 \%$.
\end{abstract}

Keywords: Malcolm Baldrige Criteria, performance measurement 
Aspek mutu pelayanan merupakanhal yang sangat penting diperhatikan karena mencerminkan tingkat keberhasilan FKTP Non Perawatan Kota Surabaya. Untuk mengetahu mutu diperlukan suatu pengukuran kinerja. Penelitian in ibertujuan untuk mengukur kinerja FKTP Non Perawatan Kota Surabaya. Penelitian ini menggunakan observasional dengan desain cross sectional. Untuk mengukur kinerja FKTP Non Perawatan Kota Surabaya, terbagimenjadi 2 jenis FKTP yaitu FKTP Non Perawatanberstandar ISO dan FKTP Non PerawatanNon ISO. Beberapa sampel dari FKTP Non Perawatan dari 2 tipe tersebut secara random dipilih beberapa FKTP, kemudian diminta untuk melakukan penilaian dengan mengisi kuisioner. Hasil penelitian dinilai berdasarkan beberapa aspek, yaitu sumber daya manusia, aspek keuangan, budaya organisasi, fasilitas pelayanan penunjang, kebijakan kesehatan, tantangan FKTP, hubungan masyarakat, ancaman pada pelayanan, teknologi dan sarana, fasilitas pelayanan medis, dan tantangan pada program pelayanan. Pada FKTP berstandar ISO, nilai tertinggi didapat dari kriteria yang sama dengan FKTP Non ISO yaitu kriteria Budaya Organisasi dengan nilai berturut-turut sebesar $91,73 \%$ dan $86,79 \%$. Untuk nilai terendah juga pada kriteria yang sama, yaitu Ancaman pada pelayanan dengan persentase FKTP ISO 56,11\% dan FKTP Non ISO 64,68\%. Dapat disimpulkan bahwa berdasar kriteria Malcolm Baldrige, kinerja FKTP ISO yang mendapatkan bobot $87,25 \%$ lebih tinggi daripada FKTP Non ISO yang memperoleh $80,83 \%$.

\section{Kata kunci: Kriteria Malcolm Baldrige, pengukuran kinerja}

\section{PENDAHULUAN}

Setiap warga negara berhak mendapatkan pelayanan kesehatan yang bermutu dan terjangkau. Hak akan pelayanan kesehatan merupakan salah satu hak mendasar dari warga negara Indonesia, sehingga pemerintah wajib menyediakan fasilitas pelayanan kesehatan yang layak. Salah satu fasilitas pelayanan kesehatan untuk masyarakat yang disediakan adalah puskesmas atau fasilitas kesehatan tingkat pertama (FKTP). FKTPmempunyai peran dan daya ungkit yang besar dalam pembangunan kesehatan Indonesia.FKTP dalam mencapai tujuannya memerlukan instrumen untuk menilai kinerja yang telah disesuaikan dengan Standar Pelayanan Minimal (SPM) atas dasar perencanaan yang telah disusunnya. Tolok ukur penilaian kinerjanya mengacu pada model sistem memperhatikan relevansi, aksesibilitas, efisiensi, efektifitas, dan dampak.

Berdasarkan data Kemenkes RI (2015) Indonesia memiliki 9.731 buah Puskesmas atau FKTP (Kemenkes RI, 2015). Propinsi Jawa Timur sendiri memiliki 960 buah yang terdiri dari 519 Puskesmas Perawatan dan 441 Puskesmas Non Perawatan (Dinkes Propinsi Jawa Timur, 2016). Dari seluruh jumlah puskesmas tersebut, 62 puskesmas terdapat di Kota Surabaya. Kota Surabaya adalah kota di Jawa Timur dengan jumlah FKTP terbanyak daripada kabupaten/kota yang lainnya. Sejumlah 16 FKTP dari 62 FKTP yang ada merupakan FKTP Perawatan dan 46 FKTP Non Perawatan. FKTP di Kota Surabaya sebagian sudah memenuhi standart ISO, sebagian belum memenuhi standart ISO.

FKTP dapat dikategorikan dalam kategori sangat berhasil, berhasil, cukup berhasil, dan tidak berhasil. Berdasarkan data peringkat kinerja FKTP di Surabaya pada tahun 2008-2010 ditemukan dua kategori, yaitu kategori berhasil dan cukup berhasil. FKTP yang termasuk dalam kategori berhasil ada 39 FKTP dari jumlah keseluruhan 53 (73,58\%). Sedangkan FKTP yang termasuk dalam kategori cukup berhasil adalah 14 FKTP dari jumlah keseluruhan 53 FKTP (26,42\%).FKTP dibagi dalam dua tipe, yaitu FKTP perawatan dan FKTP non perawatan. Pada FKTP perawatan, FKTP yang termasuk dalam kategori berhasil ada 8 FKTP dari 10 FKTP (80\%). Sedangkan FKTP yang termasuk dalam kategori cukup berhasil ada 2 FKTP dari 10 FKTP (20\%). Pada FKTP non perawatan, FKTP yang termasuk dalam 
kategori berhasil ada 31 FKTP dari 43 FKTP (72,09\%). Sedangkan FKTP yang termasuk dalam kategori cukup berhasil ada 12 FKTP dari 43 FKTP $(27,91 \%)$.

Tabel 1. Persentase keberhasilan Fasilitas Kesehatan Tingkat Pertama

\begin{tabular}{cccc}
\hline \multirow{2}{*}{$\begin{array}{c}\text { Kategori } \\
\text { Capaian }\end{array}$} & \multicolumn{2}{c}{ Tipe FKTP } & \\
\cline { 2 - 3 } & $\begin{array}{c}\text { Perawatan } \\
(\%)\end{array}$ & $\begin{array}{c}\text { Non } \\
\text { Perawatan } \\
(\%)\end{array}$ & Total \\
\hline Berhasil & 8 & 31 & 39 \\
& $(80,00 \%)$ & $(72,09 \%)$ & $(100 \%)$ \\
\hline \multirow{2}{*}{ Cukup } & 2 & 12 & 14 \\
& $(20,00 \%)$ & $(27,91 \%)$ & $(100 \%)$ \\
\hline \multirow{2}{*}{ Total } & $\mathbf{1 0}$ & $\mathbf{4 3}$ & $\mathbf{5 3}$ \\
& $(\mathbf{1 0 0 , 0 0 \% )}$ & $\mathbf{( 1 0 0 . 0 0 \% )}$ & $\mathbf{( 1 0 0 \% )}$ \\
\hline
\end{tabular}

Berdasarkan data di atas peneliti menemukan kinerja FKTP non perawatan Kota Surabaya yang masih termasuk dalam kategori cukup yaitu sebanyak 27,91\%. Pengukuran ini berdasarkan data cakupan yang dengan standart pelayanan minimal, sehinggamasalah bagi penelitiadalahbelum diketahuinyamutupelayanan FKTP baik yang sudahberstandar ISO maupun yang belumberstandar ISO ditinjaudari 7 Kriteria Malcolm

Baldrige sebagaisalahsatuupayamanajemenmututerp adudalambidangPelayananKesehatan.

Sehingga Rumusan masalah pada penelitian ini adalah bagaimana kinerja pada FKTP non perawatan Kota Surabaya? Serta, bagaimana analisis pilar Malcolm Baldrigedalam kinerja FKTP non perawatan Kota Surabaya?

Tujuan umum dari penelitian ini adalah untuk untuk mengukur kinerja FKTP non perawatan di Kota Surabaya berdasarkan kriteria Malcolm Balridge. Sedangkan tujuan khususnya antara lain (1) mengukur kinerja FKTP non perawatan Kota Surabaya dan (2) menganalisis pilar Malcolm Baldrigepada FKTP non perawatan Kota Surabaya. Peneliti berharap penelitian ini dapat memberikan manfaat bagi instansi FKTP sebagai gambaran bagi pihak instansi mengenai kinerja saat ini sehingga dapat dijadikan masukan dalam rangka meningkatkan kinerja instansi sesuai dengan kriteria yang masih dianggap kurang.

\section{PUSTAKA}

Menurut Depkes RI (2004), FKTP adalah unit pelaksana teknis dinas kesehatan Kabupaten/Kota yang bertanggung jawab menyelenggarakan pembangunan kesehatan di suatu wilayah kerja. FKTP memiliki tiga fungsi, yakni (1) pusat penggerak pembangunan berwawasan kesehatan; (2) pusat pemberdayaan masyarakat; dan (3) pusat pelayanan kesehatan strata pertama. FKTP dibagi menjadi 2 (dua) yakni perawatan dan non perawatan. Perbedaan FKTP non perawatan dengan yang perawatan hanya terletak pada ruang rawat inap yang tidak tersedia di FKTP non perawatan (Depkes RI, 2006).

Kinerja FKTP merupakan penilaian hasil kegiatan dan mutu pelayanan dari kegiatan FKTP, yang jenis dan tolak ukurnya ditetapkan oleh daerah masingmasing daerah. Menurut Dinkes Jatim (2005) Penilaian Kinerja FKTP (PKP) adalah suatu upaya untuk melakukan penilaian terhadap kinerja FKTP dengan melakukan penilaian sendiri selama 1 (satu) tahun kalender. Tujuan umum dilaksanakannya PKP adalah tercapainya tingkat kinerja FKTP yang berkualitas secara optimal dalam rangka mendukung pencapaian tujuan pembangunan kesehatan tingkat kabupaten/kota. Sedangkan tujuan khusus dilaksanakan PKP adalah mendapatkan gambaran pencapaian hasil kegiatan dan mutu pelayanan kesehatan, mendapatkan gambaran informasi sebagai bahan analisa kerja FKTP mencari permasalahan dan pemecahannya, dan FKTP mendapatkan bahan masukan untuk perencanaan tahun yang akan datang bagi FKTP dan Dinas Kesehatan kabupaten/kota.

Pelayanan kesehatan yang bermutu diselenggarakan sesuai dengan kode etik dan standar pelayanan profesi yang telah ditetapkan, sehingga dapat memberikan kepuasan kepada setiap pemakai jasa pelayanan kesehatan. Berdasarkan hasil penelitian Safrudin dkk. (2010) menyatakan bahwa mutu pelayanan kesehatan berhubungan dengan kepuasan pasien. Parasuraman dkk menyatakan mutu pelayanan kesehatan meliputi lima dimensi 
yaitu bukti fisik (tangible) kehandalan (reliability), daya tanggap (responsiveness), jaminan (assurance) dan empati (emphaty) (Muninjaya, 2014). Masalah yang sering muncul adalah keluhan masyarakat terhadap rendahnya mutu pelayanan di Puskesmas.

Malcolm Baldrige National Quality Award merupakan penghargaan atas mutu kinerja yang diberikan kepada organisasi di Amerika Serikat. Namun dalam makalah ini akan lebih membahas mengenai penilaiannya atau disebut juga Baldrige Assessment. The Baldrige Assessment adalah salah satu tools untuk meningkatkan kinerja organisasi secara keseluruhan dan terus-menerus dengan menggunakan pengukuran dan memberikan feedback mengenai kinerja organisasi dalam menyediakan produk dan jasa yang berkualitas.

Metode Malcolm baldrige memiliki kelebihan dibandingkan dengan metodepengukuran yang lain karena semua elemennya mewakili unsur dari Key Performance Index (KPI)measurement pada penilaian setiap organisasi/perusahaan. Berdasarkan Gaspersz (2002) terdapat tujuh kategori yang dinilai dalam pengukuran kinerja organisasi berdasarkan kriteria Malcolm Baldrige, yaitu: kepemimpinan (125 poin); perencanaan strategis (85 poin); fokus pelanggan (85 poin), pengukuran, analisis, dan manajemen pengetahuan (85 poin); fokus tenaga kerja ( 85 poin); fokus operasi kerja (85 poin); dan hasil kinerja (450 poin). Penilaian dari ketujuh kategori tersebut diakumulasi sehingga mendapatkan nilai tertentu. Hasil dari penilaian tersebut dikategorikan dalam tabel berikut:

Tabel 2.Jenjang predikat dan nilai skor kinerja Malcolm Baldrige

\begin{tabular}{|c|c|c|}
\hline Jenjang Predikat & Skor & Level \\
\hline EarlyDevelopment & $0-275$ & \multirow{2}{*}{ Poor } \\
\hline Early Result & $276-375$ & \\
\hline EarlyImprovement & $376-475$ & \multirow[b]{3}{*}{ Average } \\
\hline Good Peformance & $476-575$ & \\
\hline $\begin{array}{l}\text { EmergingIndustry } \\
\text { Leader }\end{array}$ & $576-675$ & \\
\hline Industry Leader & $676-775$ & \multirow{3}{*}{ Exellent } \\
\hline BenchamarkLeader & $776-875$ & \\
\hline World Leader & $876-1000$ & \\
\hline
\end{tabular}

\section{METODE PENELITIAN}

Penelitian ini merupakan penelitian observasional dengan desain cross sectional. Peneliti memperoleh data dari kuesioner yang diisi oleh kepala FKTP; kepala tata usaha, koordinator/sie pelayanan kesehatan, koordinator/sie kesehatan masyarakat; manajemen representatif; pemegang program lainnya atau petugas FKTP yang dianggap mempunyai peran penting dalam aktivitas pelayanan kesehatan di FKTP sebagai pengambil keputusan meliputi: Dokter, dokter gigi, perawat, bidan, dan petugas lainnya.

Data yang diambil dalam penelitian ini antara lain karakteristik karyawan FKTP dazn pengukuran kinerja berdasarkan persepsi karyawan FKTP menurut profil FKTP, peran kepemimpinan, perencanaan stratejik, fokus pelanggan, pengukuran, analisis, dan manajemen pengetahuan, fokus sumber daya manusia, dan fokus kegiatan operasional, serta data lain yang berkaitan dengan FKTP.

Populasi yang menjadi sasaran penelitian ini adalah seluruh FKTP Non Perawatan di kota Surabaya. Sedangkan sampel penelitian ini adalah FKTP Non Perawatan yang berstandar ISO dan yang belum berstandar ISO. Besar sampel sama dengan besar populasi karena penelitian ini digunakan untuk mengukur semua bagian dari organisasi mulai dari kepala FKTP; kepala tata usaha, koordinator/ sie pelayanan kesehatan, koordinator/ sie kesehatan masyarakat; manajemen representatif; pemegang program lainnya atau petugas FKTP yang dianggap mempunyai peran penting dalam aktivitas pelayanan kesehatan di FKTP sebagai pengambil keputusan meliputi: Dokter, dokter gigi, perawat, bidan, dan petugas lainnya.

Penelitian dilakukan di FKTP Non Perawatan Kota Surabaya yangmelibatkan dua FKTP, yakni FKTP Peneleh yang telah berstandar ISO (FKTP ISO) dan FKTP Mulyorejo yang belum berstandar ISO (FKTP Non ISO). Waktu penelitian dilaksanakan dari bulan Oktober 2012 hingga bulan Juli 2013.Peneliti melakukan penelitian dengan beberapa langkah. 
Langkah pertama dengan mengidentifikasi pengukuran kinerja berdasarkan Kriteria Malcolm Baldrige di FKTP yang meliputi: profil organisasi; kriteria kepemimpinan; perencanaan stratejik; kriteria fokus pelanggan; kriteria pengukuran, analisis, dan manajemen pengetahuan, kriteria fokus sumber daya manusia, dan kriteria hasilhasil. Setelah itu peneliti menganalisis pengukuran kinerja berdasarkan Nilai Malcolm Baldrige di FKTP Non-Perawatan Kota Surabaya. Peneliti dalam tahap terakhir akan menganalisis pilar Malcolm Baldrige dalam FKTP Non-Perawatan Kota Surabaya.Peneliti menggunakan kuesioner yang telah fixed dan dihasilkan dalam pengembangan instrumen pengukuran kinerja FKTP berdasarkan kriteria Performance Excellence Malcolm Baldrige.

\section{HASIL PENELITIAN DAN PEMBAHASAN}

\section{Gambaran Umum FKTP Peneleh (ISO)}

FKTP Peneleh beralamat di Jalan

Makam Peneleh no. 35 Surabaya. Jam pelayanan FKTP peneleh dimulai hari Senin sampai dengan Sabtu. Hari Senin sampai Kamis pelayanan berlangsung pukul 07.30 - 14.30. Hari Jumat sampai dengan pukul 11.30 dan hari Sabtu sampai dengan pukul 13.00. FKTP Peneleh melayani poli umum, poli gigi, poli kesehatan ibu dan anak (KIA), Imunisasi, Laboratorium, Spesialis Mata, Psikologi, dan pengobatan tradisional (Batra). FKTP Peneleh memiliki visi "Terwujudnya Pelayanan Kesehatan yang Optimal di Wilayah KerjaFKTP Peneleh." Misi tersebut didukung dengan tiga misi, yakni: meningkatkan kualitas sumber daya manusia; meningkatkan mutu pelayanan kesehatan yang berkesinambungan; dan meningkatkan peran serta masyarakat.

Responden untuk FKTP Peneleh terdiri dari 19 karyawan FKTP Peneleh dengan rincian 1 Kepala FKTP, 4 Perawat, 1 Perawat Gigi, 1 Analis Laboratorium, 1 Batra, 1 Psikolog, 6 Staf, 1 Sopir Ambulan, dan 3 Dokter. Karakteristik responden berdasarkan masa kerja dapat dikelompokkan sebagai berikut: lebih dari 6 tahun dengan jumlah 6 orang $(31,58 \%)$, 611 tahun sebanyak 3 orang $(15,79 \%), 12-17$ tahun sebanyak 1 orang $(5,27 \%), 18-23$ tahun berjumlah 2 orang (10,52\%), 24-29 tahun tidak ada (0\%), lebih dari 29 tahun 2 orang $(10,52 \%)$, sedangkan 5 orang $(26,32 \%)$ tidak mengisi.Data ini menunjukkan bahwa kelompok masa kerja yang paling tinggi jumlahnya adalah kurang dari 6 tahun. Berdasarkan jenis kelamin responden FKTP Peneleh mayoritas adalah perempuan dengan jumlah 15 orang $(78,95 \%)$ berbanding laki-laki 4 orang $(21,05 \%)$, yang menunjukkan bahwa responden didominasi oleh kaum perempuan. Sedangkan untuk jenjang pendidikan ditemukan rincian sebagai berikut: SD 1 orang $(5,26 \%)$, SMA 1 orang $(5,26 \%)$, D3 7 orang $(36,86 \%)$, S1 5 orang $(26,31 \%)$, dan tidak mengisi 5 orang $(26,31 \%)$, dimana responden dengan pendidikan D3 menempati urutan teratas.

\section{Gambaran Umum FKTP Mulyorejo (Non ISO)}

FKTP Mulyorejo terletak di kecamatan Mulyorejo daerah Surabaya Timur dan berdiri pada tahun 1987. FKTP Mulyorejo merupakan FKTP non perawatan yang ada di Surabaya. FKTP Mulyorejo berbatasan dengan Kecamatan Bulak di sebelah utara, Selat Madura di sebelah timur, Kecamatan Sukolilo di sebelah selatan, dan Kecamatan Tambaksari serta Kecamatan Gubeng. FKTP Mulyorejo memiliki wilayah kerja 6 kelurahan dengan luas wilayah 1.295,18 Ha. Kelurahan yang menjadi tanggung jawab dari FKTP Mulyorejo adalah Kelurahan Mulyorejo, Manyar Sabrangan, Kejawan Putih Tambak, Dukuh Sutorejo, Kalijudan, dan Kalisari. FKTP Mulyorejo memiliki visi "Pelayanan Kesehatan Masyarakat yang Optimal dan Holistik sehingga tercapai Kecamatan Sehat" yang didukung oleh 4 (empat) misi, di antaranya: menggerakkan pembangunan berwawasan kesehatan; mendorong kemandirian hidup sehat bagi keluarga dan masyarakat; memelihara dan meningkatkan mutu dan keterjangkauan pelayanan; serta memelihara dan meningkatkan kesehatan perorangan, kesehatan keluarga dan masyarakat beserta lingkungannya. 
Responden untuk FKTP Mulyorejo merupakan 19 karyawan yang meliputi 1 apoteker, 1 pelaksana farmasi, 1 perawat gigi, 2 dokter gigi, 1 perawat pelaksana, 5 bidan, 4 perawat, 1 dokter umum, 2 staf dan 1 koordinator UKM. Masa kerja responden dikelompokkan menjadi masa kerja kurang dari 6 tahun di mana terdapat 7 orang $(36,85 \%), 6-11$ tahun sebanyak 3 orang $(15,79 \%), 12-17$ tahun sejumlah 1 orang $(5,24 \%), 18-23$ tahun dengan jumlah 2 orang $(10,53 \%)$ 24-29 tahun berjumlah 2 orang $(10,53 \%)$, dan tidak ada responden yang memiliki masa kerja lebih dari 29 tahun $(0 \%)$. Selain itu terdapat 4 orang responden yang tidak mengisi $(21,06 \%)$. Data ini menunjukkan bahwa kelompok masa kerja yang paling tinggi jumlahnya adalah kurang dari 6 tahun.Berdasarkan jenis kelamin responden di FKTP Mulyorejo juga didominasi oleh perempuan dengan perbandingan 16 orang $(84,21 \%)$ dibandingkan laki-laki 3 orang $(15,79 \%)$. Jenjang pendidikan responden di FKTP Mulyorejo memiliki rincian sebagai berikut: SMA 1 orang $(5,26 \%)$, D3 8 orang $(42,10 \%)$, S1 5 orang $(26,32 \%)$, dan sebanyak 5 orang $(26,32)$ tidak mengisi.

\begin{tabular}{|c|c|c|c|}
\hline No. & Kriteria & FKTP ISO (\%) & FKTP Non ISO (\%) \\
\hline \multicolumn{4}{|c|}{ Kepemimpinan } \\
\hline 1 & Peran Kepemimpinan & 87,62 & 85,03 \\
\hline 2 & Tanggung jawab sosial & 90,00 & 81,39 \\
\hline 3 & Penyelenggaraan organisasi & 89,58 & 80,76 \\
\hline \multicolumn{4}{|c|}{ Perencanaan Strategis } \\
\hline 4 & Kinerja strategi pengembangan & 87,53 & 79,14 \\
\hline 5 & Strategi implementasi & 90,44 & 80,44 \\
\hline \multicolumn{4}{|c|}{ Fokus pada Pelanggan } \\
\hline 6 & Kondisimasyarakat & 88,67 & 81,11 \\
\hline 7 & Data pasien & 88,70 & 79,63 \\
\hline \multicolumn{4}{|c|}{ Sistem Informasi dan Manajemen } \\
\hline 8 & Sistem informasi & 89,54 & 81,85 \\
\hline 9 & Manajemen pengetahuan & 90,97 & 81,67 \\
\hline \multicolumn{4}{|c|}{ Fokus Tím } \\
\hline 10 & Sumber daya manusia & 88,01 & 86,25 \\
\hline 11 & Budaya organisasi & 91,73 & 86,79 \\
\hline 12 & Fasilitas pelayanan penunjang* & 68,89 & 70,19 \\
\hline 13 & Kebijakan kesehatan & 87,48 & 79,93 \\
\hline 14 & Tantangan FKTP & 88,81 & 80,71 \\
\hline 15 & Hubungan masyarakat & 81,59 & 77,46 \\
\hline 16 & Ancaman pada pelayanan* & 56,11 & 64,86 \\
\hline 17 & Teknologi dansarana & 82,32 & 72,32 \\
\hline 18 & Fasilitas pelayanan medis & 86,05 & 79,14 \\
\hline 19 & Tantangan pada program pelayanan & 88,57 & 78,65 \\
\hline \multicolumn{4}{|c|}{ Fokus Operasional } \\
\hline 20 & Peningkatan SDM dan lingkungannya & 87,06 & 80,40 \\
\hline 21 & Pengembangan SDM & 89,15 & 84,44 \\
\hline 22 & Proses layanan kesehatan & 88,99 & 82,12 \\
\hline 23 & Dukungan proses pelayanan & 89,17 & 81,67 \\
\hline \multicolumn{4}{|c|}{ Hasil Kinerja } \\
\hline 24 & Output kinerja proses & 89,08 & 82,03 \\
\hline 25 & Output pelayanan FKTP & 89,89 & 81,33 \\
\hline 26 & Output kepemimpinan & 92,56 & 81,44 \\
\hline 27 & Aspek keuangan & 71,78 & 66,56 \\
\hline
\end{tabular}

\section{Pengukuran Kinerja Organisasi Berdasarkan Kriteria Malcolm Baldrige Hasil pengukuran kinerja} berdasarkan kriteria Malcolm Baldrige yang meliputi 7 kategori dan 27 kriteria, hampir seluruhnya menunjukkan bahwa FKTP Peneleh (ISO) memiliki nilai yang lebih tinggi dengan pengecualian pada 2 kriteria, yakni kriteria Fasilitas Pelayanan Penunjang dan Ancaman pada Pelayanan. Keduanya termasuk dalam kategori Fokus Tim. Dua kriteria tersebut menunjukkan FKTP Mulyorejo (Non ISO) memiliki hasil lebih baik (Tabel 3).

Penilaian menggunakan kriteria Malcolm Baldrige pada FKTP Peneleh 
(ISO) dan FKTP Mulyorejo (Non ISO) menunjukkan hasil yang berbeda.Tingkat keberhasilan kinerja FKTP Peneleh pada masing-masing kategori adalah sebagai berikut: kepemimpinan dari bobot maksimal 125 mendapatkan nilai 111,15 $(88,92 \%)$; perencanaan strategis dari bobot maksimal 85 mendapatkan nilai 75,63 $(88,99 \%)$; fokus pelanggan dari bobot maksimal 85 mendapatkan nilai 75,37 $(88,66 \%)$; sistem informasi dan manajemen dari bobot maksimal 85 mendapatkan 76,71
(90,25); pembelajaran, pengembangan SDM dan proses layanan kesehatan dari bobot maksimal 85 memperoleh 74,87 $(88,08 \%)$; proses manajemen dari bobot maksimal 85 memperoleh hasil 69,94 $(82,28 \%)$; dan hasil kinerja dari bobot maksimal 450 mendapatkan nilai 408,19 (90,71\%). Jika diakumulasikan nilai yang diperoleh maka FKTP Peneleh mendapatkan nilai 891,86 atau menurut kategori MBNQA termasuk ke dalam World Leader.

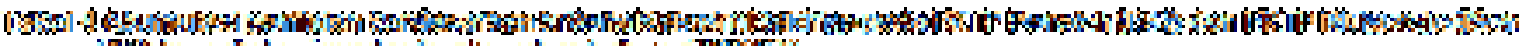

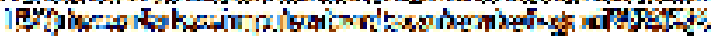

\begin{tabular}{|c|c|c|c|c|c|c|}
\hline \multirow[b]{2}{*}{ by } & \multirow[b]{2}{*}{ Exis } & \multirow{2}{*}{ Gsikis } & \multicolumn{2}{|c|}{ 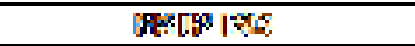 } & \multicolumn{2}{|c|}{ 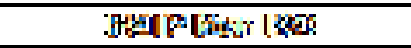 } \\
\hline & & & 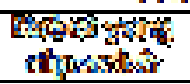 & 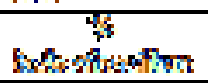 & 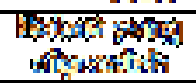 & 安 \\
\hline$\pi$ & 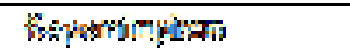 & 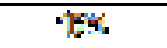 & 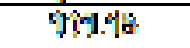 & 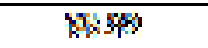 & nites & \&8\%3 \\
\hline $\overrightarrow{8}$ & 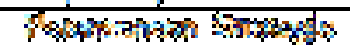 & 数. & 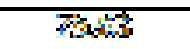 & 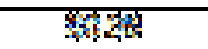 & GG & स: \\
\hline स्य & 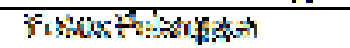 & $F$ & $2 \pi 37$ & 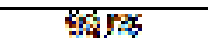 & 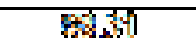 & $\operatorname{sen}$ \\
\hline a & 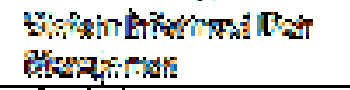 & 祭 & 的场 & $5 \%$ & MES & 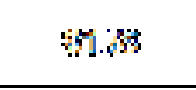 \\
\hline$\underline{z}$ & 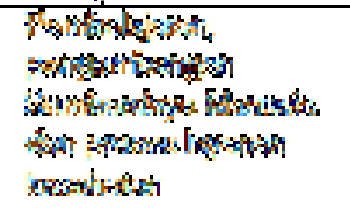 & 散 & ${ }^{2}=158$ & 絃䅦 & and $f x$ & \$ุ. \\
\hline$b$ & 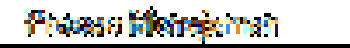 & 努 & 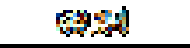 & 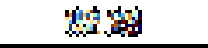 & 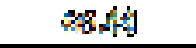 & 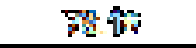 \\
\hline$\sqrt{7}$ & 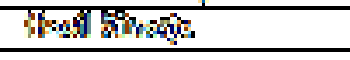 & ris & 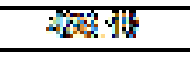 & 率柿 & $8 x-4$ & 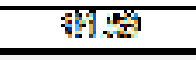 \\
\hline & lotint. & $\cos x \cdot$ & A) & & 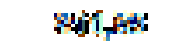 & \\
\hline & 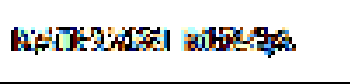 & & 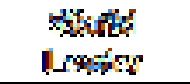 & & 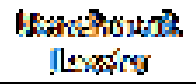 & \\
\hline
\end{tabular}

Tingkat keberhasilan kinerja FKTP Mulyorejo pada masing-masing kategori adalah sebagai berikut: kepemimpinan dari bobot maksimal 125 mendapatkan nilai $103,33(82,66 \%)$; perencanaan strategis dari bobot maksimal 85 mendapatkan nilai 67,73 $(79,68 \%)$; fokus pelanggan dari bobot maksimal 85 mendapatkan nilai 68,31 $(80,37 \%)$; sistem informasi dan manajemen dari bobot maksimal 85 mendapatkan 69,49 (81,76); pembelajaran, pengembangan SDM dan proses layanan kesehatan dari bobot maksimal 85 memperoleh 69,43 $(81,69 \%)$; proses manajemen dari bobot maksimal 85 memperoleh hasil 66,44 $(78,16 \%)$; dan hasil kinerja dari bobot maksimal 450 mendapatkan nilai 367,15 $(81,59 \%)$. Akumulasi nilai yang diperoleh FKTP Peneleh adalah 891,86 atau yang menurut kategori MBNQA masuk ke dalam Benchmark Leader (Tabel 4).Hasil penelitian terhadap variabel kepemimpinan menggambarkan bahwa visi dan misi organisasi telah ditetapkan oleh pimpinan sebagai dasar pergerakan organisasi dan visi misi tersebut selali ditanamkan kepada para karyawan agar menjadikan visi misi organisasi sebagai jiwa organisasi.Dalam sebuah organisasi, visi dan misi merupakan kunci utama untuk menjalankan segala kegiatan dalam organisasi tersebut. Visi dan misi berada dalam urutan paling atas sebelum perencanaan dalam organisasi. Visi harus diterjemahkan secara lugas dalam pernyataan misi organisasi.Misi merupakan kegiatan utama yang harus dilakukan atau fungsi yang diemban oleh suatu organisasi untuk mencapai visi yang sudah dirancang. Pernyataan misi organisasi harus cukup luas mengakomodasikan perkembangan organisasi di masa mendatang. Misi 
organisasi harus bisa menunjukkan gambaran yang akan dicapai di masa depan dengan jelas dan mudah dimengerti.

Hasil yang diperoleh terhadap pengukuran variabel perencanaan strategis merupakan salah satu hasil yang mendapatkan nilai rata-rata rendah dibawah total nilai rata-rata 7 (tujuh) variabel. Responden berpendapat bahwa FKTP Non Perawatan di Kota Surabaya masih belum mampu memenuhi unsur-unsur dalam variabel perencanaan strategis, baik dalam pengembangan strategi, maupun dalam penyebaran strategi. Gaspersz (2011) menjelaskan bahwa pengembangan strategi harus menjadi acuan organisasi untuk mempersiapkan masa depan. Pengembangan strategi dilakukan oleh pempinan dan tim yang ada dengan memanfaatkan berbagai jenis perkiraan, proyeksi, pilihan, skenario, informasi yang relevan bagi organisasi. Pengembangan strategi dapat dilakukan dengan melibatkan partisipasi mitra eksternal, pasien, dan stakeholder lain. Strategi harus mampu diterjemahkan secara luas oleh seluruh komponen internal maupun eksternal. Strategi dikembangkan/disusun untuk mencapai suatu tujuan melalui pendekatan yang komperehensif.

FKTP Non Perawatan di Kota Surabaya pada dasarnya sudah memiliki perencanaan kerja, namun perencanaan tersebut belum bersinergi dengan perencanaan strategis yang disusun oleh Dinas Kesehatan Kota Surabaya. Sebagai FKTP Non Perawatan, berdasarkan hasil wawancara dan melihat rekomendasi yang diberikan oleh surveyor akreditasi, sinergitas rencana strategis manajemen dengan rencana strategis pemilik belum dilakukan dengan baik. Persepsi responden terhadap variabel perencanaan strategis di FKTP Non Perawatan di Kota Surabaya seharusnya menjadi indikator kunci untuk meningkatkan kinerja FKTP Non Perawatan. Dengan modal status akreditasi yang telah diperoleh, seharusnya FKTP Non Perawatan di Kota Surabaya dapat mengembangkan berbagai rencana strategis, khususnya dalam meningkatkan daya saing pada saat ini dan di masa yang akan datang. Keadaan saat ini menggambarkan FKTP Non Perawatan tidak memiliki strategi yang kuat sehingga tidak mampu menjawab tantangan kompetisi dari penyelenggara pelayanan kesehatan lain yang lebih mempersiapkan diri.

Hasil penelitian ini menggambarkan kondisi yang berlangsung di FKTP Non Perawatan di Kota Surabaya dalam memenuhi unsur-unsur kriteria fokus FKTP Non Perawatan pada pelanggan/pasien berjalan dengan baik. Hampir seluruh pertanyaan dalam variabel ini memiliki nilai rata-rata diatas total nilai rata-rata seluruh variabel. Menurut responden, hal yang belum secara baik dilakukan dalam upaya untuk berfokus kepada pelanggan adalah, kurangnya FKTP Non Perawatan membuka peluang untuk menerima masukan dari pasien, baik mengenai harapan mereka, maupun keluhan-keluhan yang mereka rasakan.

FKTP Non Perawatan ini sangat diuntungkan dengan demografi pelanggan yang cenderung kurang memperhatikan aspek-aspek pelayanan prima. Pelanggan FKTP Non Perawatan ini pada umumnya memilih fasilitas pelayanan kesehatan dengan dasar pertimbangan utama biaya, dan sebagian besar loyalitasnya timbul karena pengaruh dokter yang sudah lama dikenal dengan baik. Hasil penelitian ini mengingatkan kepada manajemen tentang kurangnya penciptaan media komunikasi dengan pelanggan, namun demikian masih banyak keunggulan lain yang dapat terus dikembangkan oleh FKTP Non Perawatan dalam menjadikan pelanggan sebagai prioritas dalam segala bentuk perbaikan yang sedang dilakukan.Hasil pengukuran terhadap variabel ini menggambarkan persepsi responden bahwa FKTP Non Perawatan pada saat ini masih belum baik dalam melakukan pengukuran dan analisis kinerja untuk tujuan peningkatan kinerja. Staf FKTP Non Perawatan masih dianggap belum dapat melakukan pengukuran terhadap pelaksanaan pekerjaan yang telah dilakukannya. Dalam variabel ini keterkaitan erat dengan variabel sebelumnya, yaitu perencanaan strategis, 
terlihat dengan jelas. Pengembangan dan penterjemahan rencana strategis yang tidak baik, menyebabkan kesulitan bagi para pelaksana dalam mengukur kriteria keberhasilan pelaksanaan pekerjaan.Berdasarkan instrumen yang dimiliki oleh FKTP Non Perawatan dan rencana kerja yang telah dibuat oleh masing-masing unit kerja, seharusnya setiap karyawan mampu melakukan pengukuran secara mandiri atas hasil-hasil kerja mereka, namun belum semua karyawan dapat melakukannya secara baik. Salah satu catatn penting dalam rekomendasi surveyor akreditasi adalah terkait belum optimalnya peningkatan kompetensi karyawan secara berkesinambungan.

Dalam Kriteria Baldrige, variabel Pengukuran, Analisis dan Manajemen Pengetahuan terbagi dalam 2 (dua) sub variabel yaitu pengukuran, analisis dan peningkatan kinerja, serta sub variabel manajemen informasi, teknologi informasi dan pengetahuan. Keberadaan variabel ini memegang peranan penting untuk mensinergikan tiga variabel dalam Triad Kepemimpinan, yaitu Kepemimpinan, Perencanaan Strategis dan Fokus Pada Pelanggan/Pasien dan tiga variabel lain dalam Triad Hasil, yaitu Fokus Pada Tim, Fokus Pada Proses, dan Hasil-Hasil Kinerja Organisasi.Buruknya implementasi aktifitas pengukuran, analisis dan manajemen pengetahuan akan sangat berpengaruh pada buruknya hasi-hasil kinerja organisasi. Hasil penelitian yang tergambar pada tabel 3 memperlihatkan bahwa, ketidakmampuan organisasi untuk menginformasikan hasilhasil kinerja yang kurang optimal, membuat tidak adanya perencanaan strategis yang dipersiapkan secara khusus untuk menjawab tantangan perubahan yang sedang berlangsung.

Hasil penelitian menggambarkan persepsi responden bahwa fokus organisasi terhadap tim (karyawan) cukup baik, hal ini terlihat dari nilai rata-rata pada semua sub variabel di atas total nilai rata-rata seluruh variabel. Hal yang masih perlu mendapat perhatian adalah kurangnya kriteria dan persyaratan khusus yang menentukan seseorang dapat bergabung dalam organisasi ini sesuai kebutuhan dan rencana strategis organisasi.

Hasibuan(2001) menyatakan, pada prinsipnya seluruh anggota tim/karyawan membutuhkan motivasi untuk dapat melepaskan cadangan energi potensial yang dimilikinya. Pelepasan energi potensial seorang karyawan dalam sebuah organisasi dapat memberikan dampak yang cukup besar terhadap kemajuan organisasi. Namun hal ini akan bergantung pada motivasi yang diberikan. McClellands dalam Achievement Motivation Theory, menjelaskan hal-hal yang dapat menjadi motivasi bagi seseorang, yaitu: kebutuhan akan prestasi; kebutuhan akan afiliasi; dan kebutuhan akan kekuatan.

Bila melihat variabel kepuasan staf dibandingkan dengan kinerja FKTP Non Perawatan, maka akan muncul pertanyaan besar, mengapa dengan tingkat kepuasan kerja yang tinggi, tidak dihasilkan kinerja yang baik? Jawaban yang tepat berkaitan dengan hasil pengukuran dalam variabel terdahulu, bahwa sebagian besar karyawan sudah tidak memiliki motivasi untuk mengembangkan diri, karena sudah menempati zona nyaman dalam kehidupan mereka.Bagi FKTP Non Perawatan kepuasan karyawan dalam bekerja bukan merupakan masalah, namun manajemen dan pihak terkait harus tetap mampu memberikan motivasi kepada seluruh karyawan dan berusaha mengeluarkan mereka dari zona nyamannya, agar energienergi potensial yang mereka miliki dapat menjadi bahan bakar, bahkan menjadi bahan peledak untuk meningkatkan hasilhasil kinerja organisasi secara dahsyat.

Hasil yang didapatkan pada pengukuran variabel fokus pada proses tetap konsisten dengan beberapa pengukuran pada variabel sebelumnya. Organisasi memiliki perhatian yang besar terhadap sistem kerja dan proses kerja, namun kurang peka terhadap pemenuhan kebutuhan para karyawan, hal ini tergambar oleh peneliti setelah melihat nilai rata-rata atas jawaban pertanyaan yang lebih rendah dari total nilai rata-rata seluruh variabel. Dalam variabel fokus pada proses, keberadaan karyawan merupakan unsur 
dominan dalam sebuah proses organisasi selain material, metode maupun peralatan. Karyawan merupakan pelanggan internal yang harus mendapat perhatian sama baiknya dengan pelanggan ekstenal organisasi.

FKTP Non Perawatan sudah mulai mempersiapkan sistem kerja pada setiap unit kerjanya, namun keterbatasan mereka dalam menyediakan fasilitas bekerja yang layak masih menjadi kendala. Dengan berbagai keterbatasan yang ada, dimulai dengan pembenahan sumber daya manusia, sistem dan proses kerja FKTP Non Perawatan di Kota Surabaya mulai menyesuaikan dengan berbagai standar dan prosedur kerja yang baik. Hal ini dapat dilihat dari capaian FKTP Non Perawatan dalam proses akreditasi yang memperoleh hasil memuaskan bagi pihak-pihak yang terkait.

Konsep Baldrige bertujuan untuk mengarahkan organisasi agar memiliki fokus yang baik terhadap proses yang berlangsung, karena dengan fokus yang baik, terhadap sistem kerja maupun proses kerja akan memberikan nilai tambah bagi kemajuan organisasi, dan peningkatan hasil-hasil kinerja organisasi. Kriteria Baldrige mensyaratkan kemampuan organisasi untuk dapat mengukur peningkatan maupun penurunan hasil-hasil kinerja yang meliputi: hasil proses dan pelayanan kesehatan; hasil berfokus pelanggan; hasil berfokus tim (karyawan); hasil Kepemimpinan dan tata kelola; dan hasil Keuangan dan pasar.

Kemampuan organisasi dalam mengukur hasil-hasil kinerja akan menjadi tolok ukur utama dalam meningkatkan kinerja organisasi pada masa yang akan datang. Melalui pemenuhan unsur-unsur dalam variabel ini prinsip-prinsip manajemen mutu terpadu. Hasil penelitian yang dilakukan di FKTP Non Perawatan di Kota Surabaya menggambarkan bahwa sub variabel hasil kinerja berfokus pelanggan dan sub variabel hasil berfokus karyawan memiliki nilai ratarata lebih tinggi dari total nilai rata-rata seluruh variabel. Secara total variabel hasilhasil kinerja organisasi memiliki nilai yang lebih rendah dari total nilai rata-rata seluruh variabel, hal ini berarti hasil kinerja organisasi menurut pandangan responden masih belum baik atau belum seperti yang diharapkan, hasil yang paling buruk menurut responden adalah hasil keuangan dan pasar/konsumen.

\section{SIMPULAN DAN SARAN}

Berdasarkan kriteria Malcolm baldrige, kinerja FKTPNon Perawatan dengan standart ISO memiliki nilai lebih baik dan setingkat lebih tinggi daripada FKTPNon ISO. Ada perbedaankinerja yang perludiprioritaskanantara FKTP ISO dan FKTP Non ISO, FKTP ISO prioritaspertamadengantingkatkeberhasilan terendahadalahaspekkinerjalingkungan

FKTP,kemudian prioritas kedua adalah pembelajaran, pengembangan sumber daya manusia dan proses layanan kesehatan, prioritas ketiga adalah kepemimpinan kesehatan, prioritas keempat adalah perencanaan kesehatan, prioritas kelima sistem informasi dan manajemen. Prioritas keenam adalah nilai tertinggi dengan persentase keberhasilan tertinggi yaitu hasil kinerja FKTP.Sedangkan pada FKTP Non ISO, prioritas pertama disematkan pada kinerja lingkungan FKTP, kemudian secara berurutan adalah perencanaan kesehatan, hasil kinerja FKTP, pembelajaran, pengembangan sumber daya manusia dan proses layanan kesehatan, kemudian sistem informasi manajemen dan yang terakhir dengan tingkat keberhasilan tertinggi yaitu kepemimpinan kesehatan.

Saran dalam penelitian ini antara lain, sebaiknya FKTP memprioritaskan pada aspek-aspek unggulan yang memiliki tingkat keberhasilan tinggi dalam kriteria Malcolm Baldrige. Namun untuk perbaikan kinerja, kedua FKTP sebaiknya berfokus pada beberapa aspek kinerja yang telah menjadi prioritas.Meskipun hasil penilaian dengan nilai presetase bobot Malcolm baldrige termasuk baik, namun perlu dikaji lebih dalam lagi mengenai aspek-aspek yang terinci pada kriteria Malcolm Baldrige agar dapat mengetahui aspek kritis yang mempengaruhi baik buruknya kinerja organisasi. Bagi FKTP Non Perawatan Non 
ISO disiarankan untuk mengejarstandart ISO agar kinerjanya dapat meningkat dan lebih baik lagi. Untuk peneliti selanjutnya, diharapkan melanjutkan penelitian ini di tahun-tahun berikutnya untuk melihat apakah ada perubahan atau tidak dalam perkembangannya.

\section{DAFTAR PUSTAKA}

Haksama, S. (2011). Pengembangan Instrumen Pengukuran Kinerja Puskesmas Berdasarkan Kriteria Performance Excellence Malcolm Baldrige Di Provinsi Jakarta. Disertasi. Program Doktor Ilmu Kesehatan Masyarakat. Program Pascasarjana Fakultas Kesehatan Masyarakat, Universitas Indonesia. Jakarta

Brown, M.G. (2008). The Pocket Guide to Baldrige award Criteria. New York: CRC Productivity Press.

Notoatmodjo, S. (2007). Kesehatan Masyarakat, Ilmu dan Seni. Jakarta: PT Rineka Cipta.

Septiawan, C. (2004). Aplikasi Model Malcolm Baldrige Untuk Mengukur Persepsi Mahasiswa Terhadap Mutu Pendidikan Program Pascasarjana PS IKMUI Tahun 2004. Tesis. Depok: Universitas Indonesia.

Sihotang, A. (2007). Manajemen Sumber Daya Manusia. Jakarta: PT Pradnya Paramita.

Stoner, J.A.F., R.E. Freeman, dan D.R Gilbert JR. (1996). Manajemen Jilid I Edisi Bahasa Indonesia. Jakarta: PT INDEKS Gramedia Grup.

Amalia, Bachtiar dkk. (2010). Analisis Perbandingan Penghargaan Kkalitas Malcolm Baldrige National Quality Award Dengan European Quality Award (MBNQA vs EQA). Semarang: Universitas Diponegoro.

R. Fellisa.(2010). 7 Kriteria dari Malcolm Baldrige National Quality Award. http://vibizmanagement.com.

Diakses pada 30 Oktober 2012 pukul 15.00 WIB.
Tiffany Hanani (2012). Malcolm Baldrige Criteria for Performance Excellent.http://www.jtanzilco.com. Diakses pada 30 Oktober 2012 pukul 20.00 WIB.

Harry S.Hertz. (2011). 2011-2012 Criteria for Performance Excellence. http://www.nist.gov . Diakses pada 6 November 2012 pukul 17.00 WIB. Suharta Dewantara dkk. (2011). Evaluasi Kinerja Inisiatif Manajemen Pemeliharaan Menggunakan Kriteria Malcolm Baldrige (Suatu Pendekatan Kualitatif - Evaluatif.. Dari118.97.33.150/jurnal/files/8589 17be80dd3ff372f943f9fce9fbf8.pdf.

Dhika Yudha Perdana. (2007). Analisis Pengukuran Kinerja Perusahaan dengan Malcolm Baldrige Criteria For Performance Excellence 2007(Studi Kasus Pt. Asuransi Ekspor Indonesia Jakarta). http://Repository.Ipb.Ac.Id/Bitstrea m/Handle/123456789/18958/Perda na.\%20dhika\%20yudha_H2008.Pdf ?Sequence=3.

,Ade YolardiSaputra. (2012).Evaluasi Kinerja Pt. Balai Pustaka (Persero) Menggunakan Pendekatan Malcolm Baldrige Criteria for Performance Excellence Sebagai Upaya Perbaikan Kinerja. Http://Repository.Ipb.Ac.Id/Bitstrea m/Handle/123456789/18996/Saputr a.\%20Ade\%20Yolardi_H2008.Pdf? Sequence $=3$. Diakses pada tanggal 5 November 2012 pukul 14.00 WIB 
JURNAL ILMIAH KESEHATAN MEDIAHUSADA ｜ＶOLUME 06/NOMOR 02/OKTOBER 2017 